\title{
Antioxidant Activity and Phytochemical Contents of Some Selected Nigerian Fruits and Vegetables
}

\author{
AzeezL.", Adeoye M.D, Majolagbe T.A, Lawal A.T, Badiru R. \\ Industrial and Environmental Chemistry Unit, Chemical Sciences Department, Fountain University, Osogbo, Osun State
}

\begin{abstract}
Ten plants which are used as condiments, spices, herbs, and eaten raw in Nigeria were investigated for their antioxidant activities using 2, 2-diphenyl-1-picrylhydrazyl (DPPH) method. Phytochemicals such as totalphenols, flavonoids, $\beta$ - Carotene, and lycopene were also determined. The results showed that the highest antioxidant activity was found in Lactuca sativa $(92.62 \%)$ and Allium sativum had the lowest (4.32\%). Lactuca sativa with the lowest $\mathrm{IC}_{50}(0.26 \mathrm{mg} / \mathrm{mL})$, is the most potent vegetable of the samples analyzed. Phenolic contents of fruits and vegetables ranged from $106 \mathrm{mg}$ quercetin $/ \mathrm{g}$ of extract for Capsicum annuum to $360 \mathrm{mg}$ quercetin/g of extract for Lycopersicon esculentum (unripe) while flavonoid contents ranged from $64 \mathrm{mg}$ quercetin/g of extract for Daucus carota to $482 \mathrm{mg}$ quercetin/g of extract for Zingiber officinale. Ripe Lycopersicon esculentum and Capsicum frutescens have higher Phenolic and Flavonoid contents than the unripe ones. There was significant correlation $(\mathrm{r}=0.63, \mathrm{p}<0.05)$ between antioxidant activity and flavonoid contents but phenolic contents poorly correlate with antio xidant activity $(\mathrm{r}=0.31, \mathrm{p}<0.05)$ of samples analyzed. Zingiber officinale had the highest content of $\beta$-carotene $(66.30 \mu \mathrm{g} / \mathrm{g}$ of extract) and Allium sativum had the lowest $(2.37 \mu \mathrm{g} / \mathrm{g}$ of extract). Ripe Lycopersicon esculentum $(22.73 \mu \mathrm{g} / \mathrm{g}$ of ext ract) had the highest lycopene and Allium sativum had the lowest ( $1.23 \mu \mathrm{g} / \mathrm{g}$ of ext ract). Ripe Lycopersicon esculentum has higher lycopene and $\beta$-carotene contents than the unripe ones, but a decrease was obtained for Capsicum frutescens upon ripening. Both $\beta$-carotene and lycopene poorly correlate with antio xidant activity but significantly correlate with each other. These fruits and vegetables can be considered as good sources of antioxidants as shown by the values obtained for antioxidant activity, phenolic, flavonoid, $\beta$-carotene and lycopene contents.
\end{abstract}

Keywords DPPH Radical Scavenging, Plant Extract, Ripeness, Phenolics, Carotenoid

\section{Introduction}

Our body is constantly exposed to a variety of oxidizing agents and the body is equally inbuilt with antioxidants to cater for the free radicals generated from the oxidants thus maintaining a balance between the production of free radicals and neutralization by antioxidants. When there is imbalance between formation and neutralization of free rad icals by antioxidants, it results to oxidative stress[1-3]. Oxidative stress has been implicated in the etiology of diseases such as cardiovascular diseases and lung cancer[4-7]. Epidemiological studies have shown that regular consumption of fru its and vegetables reduces the risk incidence of chronic diseases.[8,9]. The protection that fruits and vegetables provide against diseases has been attributed to the various antioxidants contained in them. They are good sources of natural antioxidants which include carotenoids, vitamins, phenolic compounds, flavonoids, dietary glutathione, and endogenous metabolites and have been shown to scavenge singlet and

\footnotetext{
* Corresponding author:

azeez012000@yahoo.com (Azeez L.)

Published online at http://journal.sapub.org/chemistry

Copyright (C) 2012 Scientific \& Academic Publishing. All Rights Reserved
}

triplet oxygen, free radicals, enzyme inhibitors and decompose peroxides[10,11]. Phenolic compounds are secondary metabolites in fruits and vegetables. They have been reported to exhibit antioxidant activity which allows them to scavenge both active oxygen species and electrophiles, to inhibit nitrosation and to chelate metal ions, to have the potential for autoxidation and the capability to modulate certain cellular enzy me activities[12-14]. Flavonoids, a class of phenolic compounds has been shown to possess anti-inflammatory, antiviral, anticarcinogenic, antithrombotic, antiallergic and hepatoprotective[15]. Carotenes have been proved to possess antioxidant activity due to their ability to quench singlet oxygen and inhibit lipid peroxidation[16]. Thus, diets rich in fru its and vegetables are believed to play an important role in preventing diseases but human choices of diet are driven by necessity and economy. Lack of knowledge on the importance of good diet and prevalence of poverty has influenced the composition of diets taken by Nigerians. Coupled with this, the exposure to different kinds of toxic substances such as smoke from generators, second-hand vehicles and pesticide which are capable of inducing oxidative stress through production of free radicals. Thus, this study was set to determine the antio xidant activity and phytochemical contents of commonly eaten fruits and 
vegetables and to determine the difference in antioxidants components due to ripeness.

\section{Materials and Methods}

\subsection{Sampling Procedure}

Ten fruits and vegetables (Table 1) used in this study were brought from various markets in Oshogbo and identified by Mrs. F.M Tairu at National Horticultural Research Institute (NIHORT), Ibadan.

Table 1. Botanical and common/ local names of plants used in this study

\begin{tabular}{|cc|}
\hline Botanical names & Vernacular/ Common names \\
\hline Zingiber officinale & Ginger \\
Allium sativum & Ayu/Garlic \\
Cucumis sativus & Cucumber \\
Lactuca sativa & Lettuce \\
Lycopersicon esculentum & Tomati/Tomatoes (ripe) \\
Lycopersicon esculentum & Tomati/Tomatoes (unripe) \\
Capsicum frutescens & Sombo/Bellpepper (ripe) \\
Capsicum frutescens & Sombo/Bellpepper (unripe) \\
Daucus carota & Carrot \\
Capsicum annumm & Green pepper \\
\hline
\end{tabular}

\subsubsection{Standards and Reagents}

Standards: BHA (butylatedhydroxyanisol), Quercetin, Folin-ciocalteu's phenol, DPPH (2, 2-diphenyl-1-p icrylhydr azyl), were all purchased from Sigma-Aldrich, Germany. Sodium carbonate, Aluminum ch loride and Methanol were purchased fro m BDH Poole, England. All the chemicals used were of analytical grade. Deionized-Distilled water was used throughout the experiment. Jenway 6405 UV-Vis ible Spectrophotometer by Buch Scientific Inc.USA was used for analysis.

\subsection{Extraction}

The samples were rinsed with distilled water to remove sand, cut into pieces and lyophilized to remove the mo isture content. Resulting dried samples were powdered using Moulinex blender. These ground samples were extracted twice with a total volume of $100 \mathrm{ml}$ of $70 \%$ aqueous methanol. The mixture was shaken on an orbital shaker for $75 \mathrm{~min}$ at $250 \mathrm{rpm}$ and then filtered through Whatman No 1 filter paper. The combined methanolic extract was then evaporated at $55^{\circ} \mathrm{C}$ using water bath and dried to powder in a lyophilizer.

\subsection{Phytoche mical Screening}

\subsubsection{Determination of Total Phenols by Folin-Ciocalteu} Method

Total phenol content in the sample was determined using Folin-Ciocalteu method of Olajire and Azeez (2011)[17]. $0.5 \mathrm{ml}$ of the methanolic extract was added to $10 \mathrm{ml}$ distilled water and $2.5 \mathrm{ml}$ of $0.2 \mathrm{~N}$ Fo lin-Ciocalteu phenol reagent. The mixture was allowed to stand at room temperature for $5 \mathrm{~min}$ and then $2 \mathrm{ml}$ of $2 \%$ of sodium carbonate was added. The resulting solution was measured at $780 \mathrm{~nm}$. Quercetin was used as standard for the calibration curve.

\subsubsection{Determination of Flavonoid Concentration}

The $\mathrm{AlCl}_{3}$ method of Jagadish et al, 2009[18] was used for determination of the flavonoid content of the sample extract. $1.5 \mathrm{ml}$ of extract was added to $1.5 \mathrm{ml}$ of $2 \%$ methanolic $\mathrm{AlCl}_{3}$ solution. The mixture was vigorously shaken on orbital shaker for $5 \mathrm{~min}$ at $200 \mathrm{rpm}$ and the absorbance was read at $367 \mathrm{~nm}$ after $10 \mathrm{~min}$ of incubation. Reagent blank using distilled water instead of sample was prepared. Quercet in was used as standard for the calibration curve.

\subsubsection{Determination of $\beta$ - Carotene and Lycopene}

$\beta$ - Carotene and Lycopene were determined according to the method of Nagata and Yamashita (1992)[19]. The dried methanolic extract $(100 \mathrm{mg})$ was vigorously shaken with $10 \mathrm{ml}$ of acetone - hexane mixture $(4: 6)$ for $1 \mathrm{~min}$. The absorbance of the filtrate was measured at $\lambda=453,505,645$ and $663 \mathrm{~nm}$. Contents of $\beta$-Carotene and Lycopene were calculated according to the following equations: lycopene $(\mathrm{mg} / 100 \mathrm{ml})=-0.0458 \mathrm{~A}_{663}+0.372 \mathrm{~A}_{505}+0.0806 \mathrm{~A}_{453:} \beta-$ Carotene $(\mathrm{mg} / 100 \mathrm{ml})=0.216 \mathrm{~A}_{663}-0.304 \mathrm{~A}_{505}+0.452 \mathrm{~A}_{453}$. The values are expressed as $\mu \mathrm{g} / \mathrm{g}$ of extract.

\subsection{DPPH Radical Scavenging Capacity Assay}

$1 \mathrm{ml}$ of methanolic solution of the ext ract was added to $4 \mathrm{ml}$ of $0.1 \mathrm{mmo}^{-1}{ }^{-1}$ methanolic solution of DPPH. After 30min incubation in the dark at room temperature, the absorbance was read against a blank at $517 \mathrm{~nm}$. Inhibition of free radicals by DPPH in percent $\left(I_{(\%)}\right)$ was calculated using this formula:

$$
I_{(\%)}=\left[\frac{\left(A_{\text {control }}-A_{\text {sample }}\right)}{A_{\text {control }}}\right] \times 100
$$

Where $A_{\text {control }}$ is the absorbance of the control reaction and $A_{\text {sample }}$ is the absorbance of the test compound. Quercetin and BHA were used as standard controls.

\subsection{Statistical Analysis}

All results are expressed as mean \pm standard deviation. All results are means of three replicates. The data were correlated using Pearson correlation coefficient at $\mathrm{p}<0.05$. $\mathrm{IC}_{50}$ was calculated using linear regression analysis. SPSS 15 version was used for the statistical analysis.

\section{Results and Discussion}

\subsection{Results}

Table 2 presents the results obtained for antioxidant activity and $\mathrm{IC}_{50}$ of ten fruits and vegetables used. Figures 1,2 , 3 and 4 present phenolic, flavonoid, lycopene and $\beta$-carotene contents of fruits and vegetables analyzed.

\subsubsection{Antio xidant Activity}

Antioxidants activity ranged from $4.32 \pm 0.02 \%$ for Allium sativum to $92.62 \pm 0.98 \%$ for Lactuca sativa. The decreasing 
order of antioxidant activity is Lactuca sativa $>$ Zingiber officinale $>$ Capsicum frutescens (ripe) $>$ Capsicum frutescens (unripe) $>$ Capsicum annuum $>$ Lycopersicon esculentum (unripe) $>$ Lycopersicon esculentum(ripe) $>$ Cucumis sativus $>$ Daucus carota $>$ Allium sativum. $\mathrm{IC}_{50}$ which is the inhibitory concentration at which $50 \%$ of free radicals are scavenged ranged from $0.26 \mathrm{mg} / \mathrm{ml}$ for Lactuca sativa to $10.24 \mathrm{mg} / \mathrm{ml}$ for Allium sativum. The $\mathrm{IC}_{50}$ of Lactuca sativa $(0.26 \mathrm{mg} / \mathrm{ml})$, Zingiber officinale $(0.29 \mathrm{mg} / \mathrm{ml})$, ripe Capsicum frutescens $(0.67 \mathrm{mg} / \mathrm{ml})$, and unripe Capsicum frutescens $(0.74 \mathrm{mg} / \mathrm{ml})$ co mpared to standards: Quercetin $\left(\mathrm{IC}_{50}=\right.$ $0.83 \mathrm{mg} / \mathrm{ml})$, and BHA $\left(\mathrm{IC}_{50}=0.96 \mathrm{mg} / \mathrm{ml}\right)$ are lower. Antioxidants activity in these samples poorly correlates with phenolic contents $\left(r^{2}=0.31, p<0.05\right), \beta$-carotene $\left(r^{2}=0.38\right.$, $\mathrm{p}<0.05)$ and lycopene $\left(\mathrm{r}^{2}=0.05, \mathrm{p}<0.05\right)$ but significantly with flavonoid $\left(\mathrm{r}^{2}=0.63, \mathrm{p}<0.05\right)$. There was an increase in antioxidants activity increase due to ripeness in Capsicum frutescens but a decrease was obtained for Lycopersicon esculentum

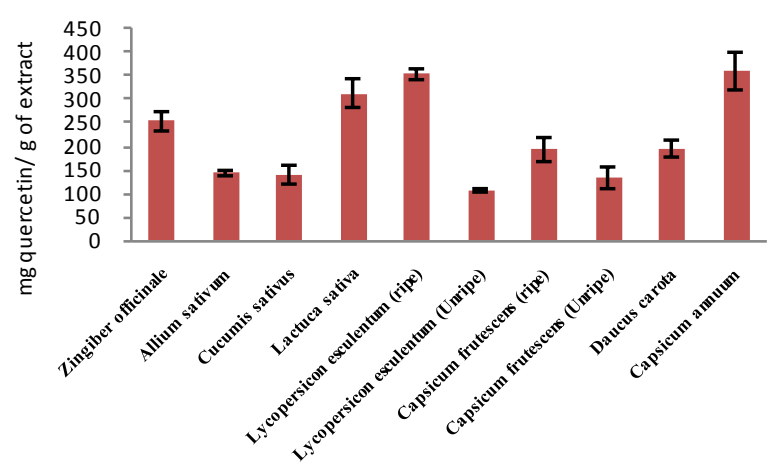

Figure 1. Total phenolic content of fruits and vegetables studied

Table 2. Antioxidant activity (AA), flavonoid, phenolics, lycopene, $\beta$ Carotene, and the $\mathrm{IC}_{50}$ of the fruits and vegetable studied

\begin{tabular}{|ccc|}
\hline Botanical names & Antioxidant Activity $^{\mathrm{a}}$ & $\mathrm{IC}_{50}{ }^{\mathrm{b}}$ \\
\hline Zingiber officinale & $88.29 \pm 2.30$ & 0.29 \\
Allium sativum & $4.32 \pm 0.02$ & 10.24 \\
Cucumis sativus & $28.34 \pm 1.23$ & 1.68 \\
Lactuca sativa & $92.62 \pm 0.98$ & 0.26 \\
Lycopersicon esculentum & $35.07 \pm 4.32$ & 1.47 \\
(ripe) & & \\
Lycopersicon esculen- & $41.10 \pm 0.57$ & 1.16 \\
tum (unripe) & $67.85 \pm 1.56$ & 0.67 \\
Capsicum frutescens (ripe) & $62.35 \pm 0.86$ & 0.74 \\
Capsicum frutescens (unripe) & $10.28 \pm 1.34$ & 4.61 \\
Daucus carota & $42.92 \pm 3.14$ & 1.15 \\
Capsicum annumm & $47.9 \pm 0.22$ & 0.96 \\
BHA & $58.96 \pm 1.85$ & 0.83 \\
QUERCETIN &
\end{tabular}

Each value is expressed as mean \pm standard deviation $(n=3) ;{ }^{a} \%$ of methanolic radical. ${ }^{\mathrm{m}} \mathrm{m} / \mathrm{ml}$ of effective concentration at which $50 \%$ of DPPH radicals are scavenged.

\subsubsection{Phytochemical Contents}

Phenolic contents of fruits and vegetables as shown in figure 1 ranged from $106.67 \pm 11.55 \mathrm{mg}$ quercetin $/ \mathrm{g}$ of extract for Capsicum annuum to $360.01 \pm 40.01 \mathrm{mg}$ quercetin/g of extract for Lycopersicon esculentum (unripe) while flavon- oid contents (figure 2) ranged from $64.06 \pm 3.46 \mathrm{mg}$ quercetin/g of extract for Daucus carota to $482.29 \pm 1.73 \mathrm{mg}$ quercetin/g of extract for Zingiber officinale. Ripe Lycopersicon esculentum and Capsicum frutescens have higher phenolic and flavonoid values than unripe

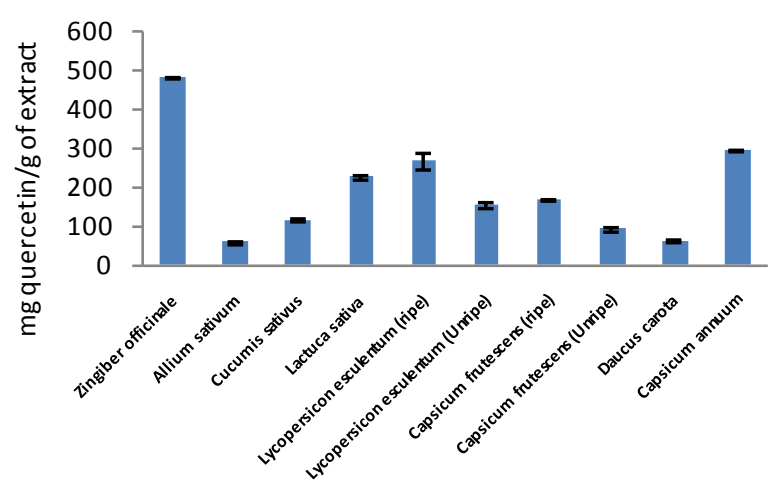

Figure 2. Flavonoid contents of fruits and vegetables analyzed

Zingiber officinale had the highest content of $\beta$-carotene $(66.30 \pm 1.45 \mu \mathrm{g} / \mathrm{g}$ of extract) and Allium sativum had the lowest $(2.37 \pm 0.27 \mu \mathrm{g} / \mathrm{g}$ of extract). Ripe Lycopersicon esculentum $(22.73 \pm 3.44 \mu \mathrm{g} / \mathrm{g}$ of extract) had the highest lycopene and Allium sativum had the lowest $(1.23 \pm 0.25 \mu \mathrm{g} / \mathrm{g}$ of extract). There was an increase in the contents of lycopene and $\beta$-carotene due to ripeness in Lycopersicon esculentum but a decrease was obtained for Capsicum frutescens.

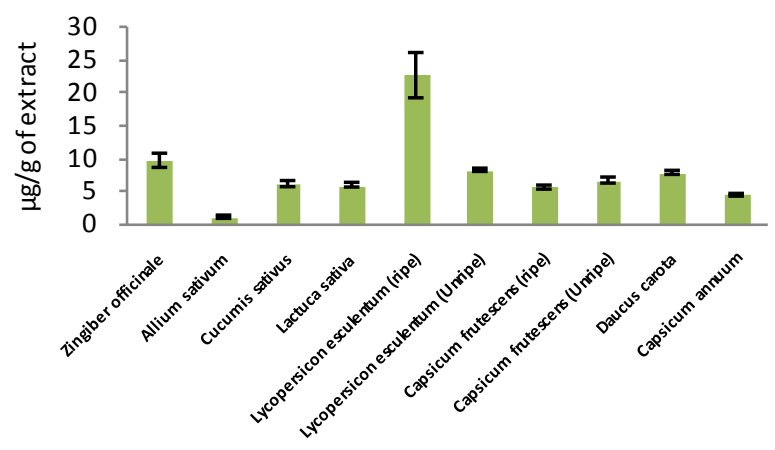

Figure 3. Lycopene contents of fruits and vegetables studied

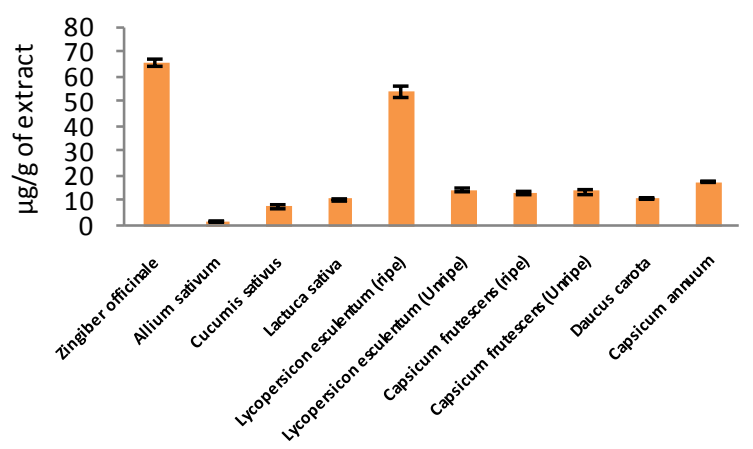

Figure 4. $\beta$-carotene contents of fruits and vegetables analyzed

\subsection{Discussion}




\subsubsection{DPPH Antio xidants}

The electron donating ability of fruits and vegetables is a suitable parameter to establish the possession of oxidative stress quenching ability and their health studies have shown that Zingiber officinale, Lactuca sativa and Capsicum frutescens are good sources of antioxidants[20-22]. $\mathrm{IC}_{50}$ of these vegetables and fruits show that they can scavenge mo re free radicals than BHA and quercetin which are standards. Zingiber officinale as obtained in this study has also been reported to inhibit better than quercetin[21]. Antioxidants capacity as found in Capsicum frutescens increased in ripe fruit and was in agreement with[20] who reported that antioxidant capacity increases with ripeness while our results for ripe and unripe Lycopersicon esculentum with decrease in antioxidant capacity due to ripeness was also in agreement with what was obtained by[23] for tomatoes with different degrees of ripeness. Though, high correlations have often been observed between phenolics and antioxidant capacity, our esults indicate that flavonoids which are a group in phenolic compounds had highest correlation coefficient with antio xidants capacity.

\subsubsection{Phytochemical Contents}

Phenolics and flavonoids have been shown to contribute significant to antioxidant ability of fruits and vegetables[20]. Especially flavonoids, have been reported to be anticancer, anti-inflammatory, antifugi, antimicrobial, antibacterial and antiviral[15]. High phenolic and flavonoid contents obtained in this study for some vegetables show that they could serve as nutritional sources for anticancer, antiviral and anti-inflammatory. Our results indicate that phenolic and flavonoid contents increased in Lycopersicon esculentum and Capsicum frutescens due to ripeness which were what Lee[24] obtained. Howard[25] also observed that flavonoid contents increased with ripeness. Our results were equally in agreement with Riadh[23] for an increase in phenolic contents due to ripeness.

Lycopene and $\beta$-Carotene possess the ability to scavenge singlet oxygen. Consumption lycopene and $\beta$-Carotene have been reported to be inverse with incidence of cancer[16]. Results obtained show that some of these vegetable contain high levels of lycopene and $\beta$-Carotene and an increase was observed for both contents in Lycopersicon esculentum due to ripeness while otherwise was observed for Capsicum frutescens. Our results are in agreement with AbdulHammed[26] and Riadh[23] who obtained increased a mount of $\beta$ Carotene and lycopene contents in the ripe than the unripe tomato.

\section{Conclusions}

The antioxidant activities, total phenol, flavonoid, $\beta$ Carotene, and lycopene contents of ten fruits and vegetables commonly consumed in Nigeria were assessed. Some of the vegetables can be considered as good sources of natural antioxidants since their extract were found to possess high antioxidant activity. This study shows that consuming ripe Capsicum frutescens and Lycopersicon esculentum would add more nutritional benefits to foods as the phytochemical contents increased with ripeness.

\section{REFERENCES}

[1] Adom, K. K., Sorrells, M. E. \& Liu, R. H. (2003). Phytochemicals and antioxidant Activity of wheat varieties. Journal of Agriculture and Food Chem. 51: 7825- 7834.

[2] Aruoma, O. I. (2003). Methodological considerations for characterizing potential antioxidant actions of bioactive components in food plants. Mutation Research: 523: 9-20.

[3] Rui Hai Liu (2004). Potential synergy of phytochemicals in cancer prevention: International research conference on Food, Nutrition and Cancer: 134: 3479S-3485S.

[4] Bhardwaj, P., Thareja, S., Prakash, S., Saraya, A. (2004). Micronutrient antioxidant intake in patients with chronicpancreatitis. Tropical Gastroenterol: 25:69-72.

[5] Atrooz, O. M. (2009). The antioxidant activity and polyphenolic contents of different plant seeds extracts. Pakistani Journal of Biological Sciences: 12: 1063- 1068.

[6] Kim, J. H; Kim, S. J; Park, H. R; In Choi, J; Cheoul, Ju Y; Chang Nam K;Kim, S. J; Lee, S. C.: 2009: The different antioxidant and anticancer activities depending on the colour of Oyster mushroom: J. Med. Plants Res: 3:1016- 1020.

[7] Rechenmacher, C. Siebel, A.M., Goldoni, A. Klauck, C.R. Sartori, T. Rodrigues, MAS Rodrigues, MT. . Gehlen, G., Ardenghi, P.G. and Silva, L.B.: 2010: A multibiomarker approach in rats to assess the impact of pollution on Sinos River, southern Brazil: Brazil Journal of Biology: 70 (4): 1223-1230.

[8] Rui Liu H: 2003: Health ben efits of fruits and vegetables are from additive and synergistic combination of phytochemicals: American Journal of Clinical Nutrition: 78: 517- 520.

[9] Du, W. D., Yuan, Z. R., Sun, J., Tang, J. X., Cheng, A. Q., Shen, D. M.: 2003:Therapeutic efficacy of high-dose vitamin $\mathrm{C}$ on acute pancreatitis and its potential mechanisms. World Journal of Gastroenterol: 9:2565-2569.

[10] Saeedeh Arabshahi-D, Vishalakshi Devi D., Asna Urooj: 2007: Evaluation of antioxidant activity of some plant extracts and their heat, $\mathrm{pH}$ and storage stability: Food Chemistry: 100: 1100-1105

[11] Pitchaon Maisuthisakul, Maitree Suttajit, Rungnaphar Pongsawatmanit: 2007: Assessment of phenolic content and free radical-scavenging capacity of some Thai indigenous plants: Food Chemistry: 100: 1409-1418

[12] Huda-Faujan, N., Noriham, A, Norrakiah, A. S. and Babji, A. S.: 2009: Antioxidant activity of plants methanolic extracts containing phenolic compounds: African Journal of Biotechnology: 8(3): 484-489

[13] Dominique Ziecha, Rodrigo Francob, Alexandros G. Georgakilasc, Stavroula Georgakilac, Vasiliki Malamou-Mitsid, Onard Schonevelde, Aglaia Pappaf, Mihalis I. Panayiotidisg,d.: 2010: The role of reactive oxy gen species and oxidative stress in environmental carcinogenesis and biomarker 
development: Chemico-Biological Interactions: 188: 334-33

[14] Kawther S. EL-Gendy, Nagat M. Aly, Fatma H. Mahmoud, Anter Kenawy, Abdel Khalek H. El-Sebae: 2010: The role of vitamin $\mathrm{C}$ as antioxidant in protection of oxidative stress induced by imidacloprid: Food and Chemical Toxicology: 48: 215-221

[15] Tapas AR, Sakarkar DM, and Kakde RB: 2008: Flavonoids as Nutraceuticals: A Review: Tropical Journal of Pharmaceutical Research: 7(3): 1089-1099

[16] Sarada S.K.S., Dipti P., Anju B., Pauline T., Kain A.K., Sairam M., Sharma S.K., Ilavazhagan G., Devendra Kumar, Selvamurthy W.: 2002: Antioxidant effect of beta-carotene on hypoxia induced oxidative stress in male albino rats: Journal of Ethnopharmacology: 79: 149-153

[17] Olajire A. A and Azeez L: 2011: Total antioxidant activity, phenolic, flavonoid and ascorbic acid contents of Nigerian vegetables: African Journal of Food Science and Technology: 2 (2): $22-29$

[18] Jagadish L. K; Krishnan V. V; Shenbha Garaman R; Kaviyasan, V. (2009). Comparative study on the antioxidant, anticancer, and antimicrobial property of agaricus bisporus imbach before and after boiling. African Journal of Biotechnology: 8: 654- 661.

[19] Nagata, M. and Yamashita, I.: 1992: Simple method for simultaneous determination of chlorophyll and carotenoids in tomato fruit: Nippon Shokuhin Kogyo Gakkaish: 39(10): 925-928.
[20] Mahmood Ghasemnezhad, Mohamad Sherafati, Gholam Ali Payvast: 2011: Variation in phenolic compounds, ascorbic acid and antioxidant activity of five coloured bell pepper Capsicum annum fruits at two different harvest times: Journal of functional foods: $3: 44-49$

[21] Stoilova I., Krastanov A., Stoyanova A., Denev P., Gargova S.: 2007: Antioxidant activity of a ginger extract Zingiber officinale: Food Chemistry: 102: 764-770

[22] Edziri H.L., Smachd M.A., Ammarc S., Mahjoub M.A., Mighric Z., Aounia M., Mastourib M.: 2011: Antioxidant, antibacterial, and antiviral effects of Lactuca sativa extracts: Industrial Crops and Products: 34: 1182-1185

[23] Riadh Ilahy a,b, Chafik Hdider, Marcello S. Lenucci, Imen Tlili, Giuseppe Dalessandro: 2011: Antioxidant activity and bioactive compound changes during fruit ripening of high-lycopene tomato cultivars: Journal of Food Composition and Analy sis: 24: 588-595

[24] Lee, Y., Howard, L. R., \& Villalon, B.: 1995: Flavonoids an antioxidant activity of fresh pepper Capsicum annum cultivars: Journal of Food Science: 60: 43: 476.

[25] Howard, L. R., Talcott, S. T., Brenes, C. H., \& Villalon, B.: (2000): Changes in phytochemical and antioxidant activity of selected pepper cultivars (Capsicum species) as influenced by maturity: Journal of Agricultural and Food Chemistry: 48: 1713-1720.

[26] Abdul-Hammed M, Bello .IA and A.A Olajire: 2009: Comparison of biochemical and physiological properties of Nigerian tomato fruits ripened under different conditions: African journal of food agriculture, nutrition and development: 9 (9): $1858-1877$ 